\title{
correspondence
}

\section{Ball lightning}

SIR,-Ball lightning is a relatively rare phenomenon, usually occurring under conditions of very strong electrical fields and usually associated with storms, though not necessarily in the storm area. The balls can be from onc inch to several feet in diameter and can have various colours. Some explode violently and some fizzle out quietly. The balls move through the air, apparently independent of wind and gravity, and are known to enter structures-even through a metal window screen and into a metal aircraft. There is no good theory to explain ball lightning, but J. R. Powell and D. Finkelstein are working on a d.c. field theory in which a strong electric field adds energy to the ball to sustain it (Structure of Ball Lightning, Brookhaven National Laboratory, Upton, New York)

Little is known about the ignition hazard of ball lightning, but in the course of investigating accidents in the past ten years, we have heard the following statements from witnesses:

- Distillate was being loaded into the open top of an 8,000 gallon transport truck. "A ball of light travelled along the fill pipe and down the droptube. It entered the truck compartment and the truck blew up."

- Solvent was being loaded through closed piping into the bottom of a 7,600 gallon transport truck. "A ball of light followed along the fill pipe toward the truck and disappeared. Then the truck blew up."

- An observer on a ship several miles from an empty VLCC (very large crude carrier) tanker. "A ball of light travelled along the deck of the ship and disappeared. Then the ship blew up."

- Jet fuel was heing loaded into the open top of a transport truck. "A ball of light entered the truck compartment and it blew up."

- A retired New York City fireboat captain, Charles Wilson of Codan Marine Inc., New York. "I know of three cases where a ball of light was reported to have moved across the deck of a barge just before the barge blew up."

- A tanker captain with the same corporation, Captain Wykoff, reportedly "saw a ball of light move across the deck toward a compartment before it blew up."

Taken individually, these are each incredible and are usually ignored by safety experts. Since there are these eight cases reported by separate observers, it appears that ball lightning might be an infrequent and unrecognised source of ignition.

There probably are other incidents, and we are soliciting any information that others may have. Our concern is that this is an unrecognised source of ignition in fuel transport operations and that conventional protective methods may be inadequate.

\section{GinsBURGH}

W. L. BULKLEY

Amoco Oil Research Department.

Naperville, Illinois 60540

\section{Forecasting error}

SIR,-Kenneth Mellanby, in a short but cogent article ("Forecasting Error", August 5, page 441), is highly critical of the state of the art of forecasting many of the social and economic components of present society.

Most of his strictures are only too true. I would however take issue with his implication that "only some form of rigid totalitarianism could improve the statistics". This can surely be tested by examining the forecasting skills of societies which have for some time displayed this characteristic. To my knowledge there is no evidence that they do have a greater predictive success rate; in fact the impression is quite the reverse.

To improve data sources used in predictions would involve the public as individuals and groups in providing information on present and intended actions and aspirations which, for various reasons, they are unwilling to divulge with any degree of spontaneity. At least part of this unwillingness stems from a sense of isolation from the decision-taking which would (hopefully) be based on the information. If truly participatory decision-taking processes existed, after a due period of time to allow for cultural inertia, the inclination to provide adequate information from which to derive alternative policy plans might well emerge.

Better data require more democracy, not less.

David R. Cope

University of Nottingham, UK

\section{Mistaken parameter}

SIR,-Politicians and others have been criticised in the national press for the misuse of the word "parameters", but I have yet to see similar charges levelled against scientists who have much less excuse for this practice. During the past three years the tendency to describe components, factors, attributes and so on as parameters has become frequent in most scientific journals, covering agricultural research and related fields, published in the UK and abroad.

To anyone in the habit of using parameters with gay abandon I would recommend the definition given by Professor D. J. Finney in An Introduction to Statistical Science in Agriculture:

"Numerical values that serve... to identify a particular distribution curve, as a member of a whole family, are termed parameters..."

I would predict that if the term were restricted to numerical values, without any greater precision of meaning, the frequency with which it is used would be halved.

\section{G. MONTGOMERIE}

Mycology Section,

Scottish Horticultural Research

Institute, Dundee, UK

\section{Electrifying demonstration}

SIR,-The theoretical approach by Marble, MacVicar and Roberts (Correspondence, July 15, page 171) is nct necessary. For many years, when teaching electrostatics to first year students, I used to stand on a $5 \mathrm{~cm}$ thick block of paraffin wax and charge myself up from a small Van de Graaf generator capable of giving 300,000 volts on open circuit. This made my hair stand on end in a convincing manner, and the sparks which I could get from a hand-held object to earth would certainly have ignited any explosive gas mixture.

Without wishing to compete with the above authors in numbers of significant figures, I must have reached between 100,000 to 200,000 volts with respect to Earth without harm--incidentally illustrating for the sake of the students the old GEC adage: "It's the amps, not the volts, wot kills yer".

\section{J. H. Fremlin}

Department of Physics,

University of Birmingham, $U K$ 